\title{
Treatment Fidelity of a Nurse-Led Motivational Interviewing-Based Pre-Treatment in Pain Rehabilitation
}

\author{
Vera-Christina Mertens, MPhil \\ Lars Forsberg, PhD \\ Jeanine A. Verbunt, MD, PhD \\ Rob E. J. M. Smeets, MD, PhD \\ Mariëlle E. J. B. Goossens, PhD
}

\begin{abstract}
Treatment fidelity and proficiency of a nurse-led motivational interviewing (MI)-based pretreatment and control condition was evaluated. A random sample was scored by means of the Motivational Interviewing Treatment Integrity (MITI) scale, and a second rater was in charge. MI fidelity was satisfactory for three out of five ratings. Most mean ratings were higher in the MIbased intervention, but differences were not statistically significant. The threshold for beginning MI
\end{abstract}

Address correspondence to Vera-Christina Mertens, MPhil, Research Unit INSIDE, Institute for Health and Behaviour, University of Luxembourg, 11, Porte des Science, L-4366, Esch-sur-Alzette, Luxemburg. Phone: +352 466644 6373; Email: verachristina.mertens@uni.lu.

Vera-Christina Mertens, MPhil, Department of Rehabilitation Medicine, Maastricht University, School for Public Health and Primary Care (CAPHRI), Postbus 616, Maastricht, The Netherlands. Phone: +352 466644 6373; Email: verachristina.mertens@uni.lu

Jeanine A. Verbunt, MD, PhD, Department of Rehabilitation Medicine, Maastricht University, School for Public Health and Primary Care (CAPHRI), Postbus 616, Maastricht, The Netherlands. Email: jeanine.verbunt@maastrichtuniversity.nl

Rob E. J. M. Smeets, MD, PhD, Department of Rehabilitation Medicine, Maastricht University, School for Public Health and Primary Care (CAPHRI), Postbus 616, Maastricht, The Netherlands. Email: r.smeets@maastrichtuniversity.nl

Mariëlle E. J. B. Goossens, PhD, Department of Rehabilitation Medicine, Maastricht University, School for Public Health and Primary Care (CAPHRI), Postbus 616, Maastricht, The Netherlands. Email: marielle.goossens@maastrichtuniversity.nl

Lars Forsberg, PhD, Department of Clinical Neuroscience, Karolinska Institute, Stockholm, Sweden. Email: lars.forsberg.3@ki.se

Jeanine A. Verbunt, MD, PhD, Adelante Centre of Expertise in Rehabilitation and Audiology, Postbus 88, Hoensbroek, The Netherlands. Email: jeanine.verbunt@maastrichtuniversity.nl

Rob E. J. M. Smeets, MD, PhD, Adelante Centre of Expertise in Rehabilitation and Audiology, Postbus 88, Hoensbroek, The Netherlands. Email: r.smeets@maastrichtuniversity.nl

Jeanine A. Verbunt, MD, PhD, Department of Rehabilitation Medicine, Maastricht University Medical Center (MUMC+), Postbus 5800, AZ Maastricht, The Netherlands. Email: jeanine.verbunt@maastrichtuniversity.nl

Rob E. J. M. Smeets, MD, PhD, Department of Rehabilitation Medicine, Maastricht University Medical Center (MUMC+), Postbus 5800, AZ Maastricht, The Netherlands. Email: r.smeets@maastrichtuniversity.nl

Mariëlle E. J. B. Goossens, PhD, Faculty of Psychology and Neurosciences (FPN), Department of Clinical Psychological Sciences (CPS), Maastricht University, Postbus 616, Maastricht, The Netherlands. Email: marielle.goossens@maastrichtuniversity.nl

Journal of Behavioral Health Services \& Research, 2015. 459-473. (C) 2015 The Author(s). This article is published with open access at Springerlink.com DOI 10.1007/s11414-015-9485-4 
proficiency was only exceeded for one score and one additional measure. In general, higher levels of fidelity in the intervention condition confirmed that MI was partially applied there. Although the quality of MI delivery as well as mixed inter-rater reliabilities of the fidelity scores leaves room for improvement, robust findings between the two raters were found. These results suggest the need for rigor selection of MI counselors on beforehand, and continuous supervision. Furthermore, fidelity check in studies using MI is needed.

\section{Introduction}

Motivational interviewing (MI) is a person-centered form of counseling to elicit and strengthen motivation for change. ${ }^{1}$ Motivation and adherence challenges are not unique to addiction treatment, wherein the historical roots of MI lay, but MI is also promising for other applications such as to promote treatment adherence. ${ }^{2}$ Several systematic reviews and meta-analyses showed the effectiveness of Motivational interviewing across behaviors and contexts in health care. ${ }^{3-6}$ The effect of MI as pre-treatment has specifically been acknowledged. ${ }^{3,4,7}$ Positive effects in pain rehabilitation treatment ${ }^{8-11}$ and moderate quality evidence have been provided for its successful application to promote physical activity in people with chronic health conditions. ${ }^{12}$

MI has two components: (1) the relational component consists of the so-called MI spirit, a counselor-attitude characterized by genuine interest in the client and empathy; (2) the technical component consists of techniques to evocate, elicit, and reinforce change talk ${ }^{13}$ (by, e.g., the use of open questions and reflections). However, so far, MI has mostly been emphasized as a spirit rather than a technique. ${ }^{14}$ At first sight, MI principles - asking open questions, giving reflections - look simple. But, the underlying principles resulting in MI spirit like empathy are a complex mix of skills that take considerable time to learn. ${ }^{1}$ As a consequence, the quality of MI delivery can vary tremendously. Since the quality of MI delivered is an important factor for the beneficial effect, this diversity can have a huge impact. ${ }^{15}$ For this reason, it is very important to check and accurately test whether MI is delivered as intended, ${ }^{16,17}$ or, in other words, to check its treatment fidelity (sometimes referred to as treatment integrity).

This can have important implications for the conclusion drawn regarding effectiveness. For example, results could be related to something else than the hypothesized working mechanism of the MI intervention because of non-adherence to procedures or failing therapist competence.

From a few other studies, it is known that MI fidelity measures have predictive validity to predict patient behavior following MI treatment. ${ }^{18-20}$ Additionally, in terms of therapists' competence, MI training is related to MI fidelity by suppressing MI countering responses related to resistance and poorer outcome which has been linked to increased change talk which in turn predicts behavior change in MI. ${ }^{20}$

As MI practitioners seem to overestimate their functioning, self-report of MI fidelity can be seen as unreliable. ${ }^{21,22}$ Furthermore, fidelity measures can serve as manipulation check to discriminate MI reliably from non-MI-based control interventions. ${ }^{23}$ Thus, quality assurance based upon recordings of the actual sessions and the usage of MI-specific coding instruments can estimate whether MI was actually delivered.

However, regardless this hypothesized impact of variety in MI quality delivered, only $17 \%$ of research specifically within the field of MI research assessed fidelity adequately. ${ }^{5}$ In the domain somatoform disorders and of research in chronic pain specifically, two of the four studies using MI checked for treatment fidelity ${ }^{8,9}$ and two other studies did not. ${ }^{10,11}$

The aim of the present study is to evaluate the treatment fidelity of an MI-based intervention and an educational control treatment in pain rehabilitation. It is hypothesized that MI proficiency will be higher in the intervention condition and that the intervention condition can be distinguished from a non-MI-based educational control condition. 


\section{Methods}

This study is part of a large two-armed randomized controlled trial (RCT) (a detailed description of the RCT is given in detail elsewhere). ${ }^{24}$ This study assessed the effectiveness of a nurse-led MI-based pre-treatment compared to an attention-control pre-treatment pain education in a Dutch chronic musculoskeletal pain population before the start of the actual pain rehabilitation treatment.

In Table 1 , an overview of the content of both study conditions is given. ${ }^{24}$

\section{Training of the nurses}

Nurses provided one treatment condition only and were trained specifically for the intervention they had to deliver.

Training for the intervention (motivational interviewing based pre-treatment (MIP)): in the MIP condition, the nurses were both experienced MI coaches. In two half-day sessions, the nurses' MI knowledge and experience in the context of chronic pain rehabilitation was updated based on an

\section{Table 1}

Main features of the two interventions

\begin{tabular}{|c|c|c|}
\hline & $\begin{array}{l}\text { Motivational interviewing based } \\
\text { pre-treatment (MIP) }\end{array}$ & $\begin{array}{l}\text { Pain education pre-treatment (Usual } \\
\text { Care, UC) }\end{array}$ \\
\hline Goal & $\begin{array}{l}\text { Explore participant's life situation, } \\
\text { impairments and ambivalences in } \\
\text { order to enhance intrinsic } \\
\text { motivation }\end{array}$ & Provide the participant with information. \\
\hline Basic principle & Motivational Interviewing & Health education and patient education. \\
\hline Foundation & $\begin{array}{l}\text { Content based on patient-driven } \\
\text { topics derived from the ICF- } \\
\text { model }\end{array}$ & $\begin{array}{l}\text { Content based on the book 'De pijn de } \\
\text { baas' (Mastering pain). }\end{array}$ \\
\hline Protocol rigidity & $\begin{array}{l}\text { Content sessions tailored to the } \\
\text { patients' readiness to change }\end{array}$ & $\begin{array}{l}\text { Content sessions is fixed by means of the } \\
\text { treatment protocol. }\end{array}$ \\
\hline \multicolumn{3}{|l|}{ Content $1^{\text {st }}$ session } \\
\hline & $\begin{array}{l}\text { Exploration actual (life) situation, } \\
\text { burden and impairments of the } \\
\text { chronic pain in daily life. } \\
\text { Assessing \& enhancing motivation, } \\
\text { self-efficacy, and readiness to } \\
\text { change for behaviour. }\end{array}$ & $\begin{array}{l}\text { Provision of general health education } \\
\text { about topics related to chronic pain. } \\
\text { Provision of information regarding core } \\
\text { elements of pain rehabilitation. }\end{array}$ \\
\hline \multicolumn{3}{|l|}{ Content $2^{\text {nd }}$ session } \\
\hline & $\begin{array}{l}\text { Giving feedback adapted to the } \\
\text { state of readiness-to-change. } \\
\text { Continuation exploration. } \\
\text { Continuation assessing \& } \\
\text { enhancing motivation, self-efficacy, } \\
\text { and readiness to change for } \\
\text { behaviour. }\end{array}$ & $\begin{array}{l}\text { Continuation of general health education } \\
\text { about topics related to chronic pain. }\end{array}$ \\
\hline Feedback & $\begin{array}{l}\text { Is given related to the stage of } \\
\text { change of the participant } \\
\text { according to the MI-principles. }\end{array}$ & Is not given. \\
\hline
\end{tabular}


evidence-based MI training tailored to their specific needs. The training was provided by a certified MI trainer. Follow-up training during the trial consisted of regular supervision (three half-days during the trial period of 1,5 years). The training was based upon actual cases and by providing direct feedback on audio taped MIP sessions by the same MI trainer.

Training for the Control Condition The two nurses of the pain education control condition were experienced in the field of (pain) rehabilitation and received a 3-h refresher training in communication skills and general principles of health education. In addition, the content of relevant chapters of the book "Mastering pain" was discussed. Follow-up training included two sessions lasting $2 \mathrm{~h}$ in which problems encountered were discussed.

\section{Measurement instrument: MITI and procedures of scoring}

To test the treatment integrity the Motivational Interviewing Treatment Integrity (MITI, version 3.1.1) scale was used. ${ }^{25}$ This scale has shown to be reliable $23,26-28$ and valid. ${ }^{25,28}$ The MITI focuses exclusively on therapist's functioning (Fig. 1). ${ }^{23}$

The MITI assessment instrument is composed of two different parts: "global counselor ratings" and "behavior counts" (see Fig. 1). Both were evaluated and rated during the preselected 20-min-long session sample in two separated rounds. Coding in the first round was performed without interruption. In the second round, each utterance was categorized in one of the five counselor-related behavior counts, and the total frequency of each specific behavior such as "giving information" was counted. ${ }^{28}$ After those two rounds of rating, five summary scores were calculated and compared to existing thresholds to evaluate fidelity finally (see end of this section).

\section{First round: global counselor ratings}

The MITI's global counselor ratings were designed to capture the rater's overall impression of the session and cover five aspects: (1) evocation, (2) collaboration, (3) autonomy/support, (4) direction, and (5) empathy. A five-point scale ranging from 1 (low) to 5 (high) has to be scored by the assessor. A precise definition of each variable can be found in the MITI's manual. ${ }^{25}$

\section{Second round: behavior counts}

Next, the assessor counted the total frequency of five categories of verbal behavior: (1) giving information, (2) MI adherent responses (i.e., asking permission, emphasizing control, affirming, or supporting), (3) MI non-adherent responses (i.e., advising without permission, confronting, or directing), (4) question (open vs. closed), and (5) reflection (simple vs. complex). ${ }^{25}$

\section{MITI summary scores and belonging thresholds for beginning proficiency}

After the two rounds, five indices (MITI summary scores) were calculated to evaluate MI fidelity. One is gained from the global counselor ratings: MI spirit. Four were gained from the behavior counts: (1) percentage of open questions, (2) percentage of complex reflections, (3) percentage of MI adherent responses, and (4) a reflections-to-questions ratio.

After this, the summary scores were checked against the thresholds score for "beginning proficiency" level. ${ }^{25}$ This threshold was defined as follows: "beginning proficiency" needs at least 3.5 points (out of 5) for the global score spirit, and a "reflection to question ratio" of 1 . The 


\section{Figure 1}

The MITI coding form

Motivational Interviewing Treatment Integrity Code (MITI) Coding Sheet

\begin{tabular}{|c|c|c|c|c|c|}
\hline \multicolumn{6}{|c|}{$1^{\text {st }}$ round: Global Counselor ratings } \\
\hline & Abbreviation & Rating & & & \\
\hline Evocation & (E) & $\begin{array}{l}1 \\
\text { Low }\end{array}$ & 3 & 4 & $\begin{array}{r}5 \\
\text { High }\end{array}$ \\
\hline Collaboration & (C) & $\begin{array}{ll}1 & 2 \\
\text { Low }\end{array}$ & 3 & 4 & $\begin{array}{r}5 \\
\text { High }\end{array}$ \\
\hline $\begin{array}{l}\text { Autonomy/ } \\
\text { Support }\end{array}$ & $(\mathrm{A} / \mathrm{S})$ & $\begin{array}{l}1 \\
\text { Low }\end{array}$ & 3 & 4 & $\begin{array}{r}5 \\
\text { High }\end{array}$ \\
\hline Direction & & $\begin{array}{lr}1 & 2 \\
\text { Low }\end{array}$ & 3 & 4 & $\begin{array}{r}5 \\
\text { High } \\
\end{array}$ \\
\hline Empathy & & $\begin{array}{ll}1 & 2 \\
\text { Low }\end{array}$ & 3 & 4 & $\begin{array}{r}5 \\
\text { High } \\
\end{array}$ \\
\hline
\end{tabular}

\begin{tabular}{|c|c|c|}
\hline \multicolumn{3}{|c|}{$2^{\text {nd }}$ round: Behavior Counts } \\
\hline & & $\mathrm{Nr}$. of counts \\
\hline $\begin{array}{l}\text { Giving } \\
\text { Information }\end{array}$ & Giving Information (GI) & \\
\hline MI Adherent & $\begin{array}{l}\text { Asking permission, affirm, emphasize } \\
\text { control, support. (MIA) }\end{array}$ & \\
\hline MI Non-adherent & Advise, confront, direct. (MINA) & \\
\hline \multirow[t]{3}{*}{ Question } & Closed Question (CQ) & \\
\hline & Open Question (OQ) & \\
\hline & Total Questions (CQ+OQ) & \\
\hline \multirow[t]{3}{*}{ Reflection } & Simple Reflection (SR) & \\
\hline & Complex Reflection (CR) & \\
\hline & Total reflections (SR+CR) & \\
\hline
\end{tabular}

\begin{tabular}{|l|l|l|l|}
\hline \multicolumn{4}{|l|}{ MITI Summary Scores and belonging thresholds } \\
\hline & Calculation & $\begin{array}{l}\text { Threshold } \\
\text { beginning proficiency }\end{array}$ & \\
\hline Global spirit & $(\mathrm{E}+\mathrm{C}+\mathrm{A} / \mathrm{S}) / 3$ & $\phi 3.5$ & \\
\hline \% Open Questions & $\mathrm{OQ} /(\mathrm{OQ}+\mathrm{CQ})$ & $50 \%$ & \\
\hline \% Complex Reflections & $\mathrm{CR} /$ Total reflections & 1 & \\
\hline $\begin{array}{l}\text { Reflections: Questions- } \\
\text { ratio }\end{array}$ & $\begin{array}{l}\text { Total reflections/ Total } \\
\text { questions }\end{array}$ & $40 \%$ & \\
\hline \% MI Adherent & MIA/ (MIA+ MINA) & $90 \%$ & \\
\hline
\end{tabular}

\begin{tabular}{|l|l|l|l|}
\hline Two additional MI-fidelity measures and belonging thresholds \\
\hline & Derived from & Threshold & \\
\hline Empathy & Global Counselor Ratings & $\phi 3.5$ & \\
\hline MI Non-adherent & Behavior count & As low as possible & \\
\hline
\end{tabular}


"percentage of open questions" and "complex reflections" had to be at least 50 and $40 \%$, respectively. And finally, the "percentage of MI adherent behaviors" had to be $90 \%$.

\section{Two additional MI fidelity measures and belonging thresholds}

Furthermore, as empathy and MI non-adherent behaviors are specifically mentioned as predictors for successful treatment, ${ }^{20,29}$ both were considered of such importance that they were also taken into account in the evaluation of MI fidelity. This was done by checking whether empathy crossed the threshold of the other global counselor ratings (namely 3.5), and counting the amount of MI non-adherent responses (being as low as possible as avoiding MI non-adherent responses might be more important than using MI adherent responses). ${ }^{25}$

\section{Procedures of the sampling}

All sessions (intervention and control condition) were audio taped, and a random sample of $20 \%$ $(n=64)$ was used to test treatment fidelity. To collect this sample, randomization of audio taped samples was stratified for the first and second sessions, as well as for intervention and control condition. In case the actual audiotape was not available due to non-consent of the participant to record $(n=4)$ or technical problems $(n=12)$, the consecutive tape of the next participant was chosen. A research assistant selected the 20-min session.

All the selected samples were scored by the first rater (VCM), and half of these recordings $(n=32)$ were also scored by a second rater $(\mathrm{JJ})$ blinded for group allocation.

\section{Ethics}

The study was approved by the Medical Ethical the University Hospital Maastricht and Maastricht University. The study is registered in a public trial registry (Nederlands Trial Register NTR 3065). All participants provided written informed consent for as well study participation as well as audio recording of the sessions.

\section{Training of the MITI raters}

Before the start of the study, both raters received initially a 40-h training program in MITI coding according to Moyers et $a{ }^{25}$ Furthermore, both raters were re-trained at the start of the coding work by using English-spoken training materials from the Center for Alcoholism, Substance Abuse and Addictions (CASAA, University of New Mexico), and worked under supervision of an employee of one of the existing MI coding labs, MIC lab, Karolinska Institutet, Stockholm, Sweden.

Furthermore, the first six double-coded sessions served as training material. Reliability of both raters was stated two times: (1) before the start of the actual rating by calculating ICCs between the two raters and the coding lab's rating who served as "gold standard" on similar English-spoken training materials; (2) during the actual rating, reliability was stated also (see section Statistical analysis).

During the period of rating, the first rater (VCM) participated in weekly intervision of the coding lab and could furthermore consult experienced raters. Thirty-two sessions (19 intervention conditions, 13 control conditions) were independently scored by the second rater (JJ). 


\section{Scoring double-coded sessions}

For the double-coded sessions, the raters scored the sessions independently and also had to reach consensus for the global counselor ratings afterward. To score the behavior counts, the arithmetic mean was calculated. In the following, this is referred to as consensus approach.

\section{Statistical analysis}

To evaluate MI quality in both study conditions, scores on all MITI domains were interpreted according the manual and belonging thresholds, ${ }^{25}$ and the two additional MI fidelity measures.

To test for differences in MI fidelity scores between conditions, an independent $t$ test (significance level of 0.05) was used. In case of non-normal distribution of either sample of the first or the second rater, the Mann-Whitney test was used.

Inter-rater reliability was calculated based on the intraclass correlation coefficients (ICCs) ${ }^{30}$ by means of a two-way mixed effects ICC model (absolute agreement) and interpreting single measures in the SPSS output. Inter-rater reliability was classified according Cicchetti and Sparrow (1981) who indicated ICC $<0.40$ as poor, $0.40-0.59$ as fair, $0.60-0.74$ as good, and $0.75-1.00$ as excellent. ${ }^{30}$ Furthermore, in case of an ordinal scale (present the global counselor ratings) Krippendorff's alpha (KALPHA) ${ }^{31}$ was also calculated by using a macro. ${ }^{32}$

Post hoc comparisons took place on nurse level in order to get more insights in nurse-specific fidelity.

Data were analyzed using Statistical Software Package for Social Sciences (SPSS), version 21 (SPSS Inc., Chicago, IL).

\section{Reliability/sensitivity analysis}

Sensitivity analysis consisted of two subsequent steps: 1) Checking inter-rater reliability between the results of the double-coded sessions and, 2) comparing the results of two approaches of the ratings: Ratings of the first rater with the second rater as well as a consensus approach between the two raters.

\section{Results}

The four nurses of both conditions participating in this study were experienced in the working field of (pain) rehabilitation. The two nurses of the MI-based intervention condition had 4 years of experience with MI; the two nurses of the educational control condition had experience with patient education in rehabilitation care.

A random sample $n=64$ of all nurse-led sessions ( $n=37$ intervention conditions, $n=27$ control conditions) was scored by the first rater (VCM). Out of this sample, $n=26$ sessions (18 intervention conditions, 8 control conditions) were also scored by a second rater (JJ). Six sessions were used as training material at the start of the double coding.

\section{Overall Results}

\section{Global counselor ratings}

According to the MITI, the nurses' beginning proficiency competence in the use of MI was satisfactory for the global counselor ratings direction (intervention as well as control condition), and empathy and evocation (intervention condition only).

Table 2 shows that all mean global counselor ratings were, except for direction (0.18), higher (between 0.34 and 1.97 points higher on a five-point Likert scale) in the MI-based intervention 


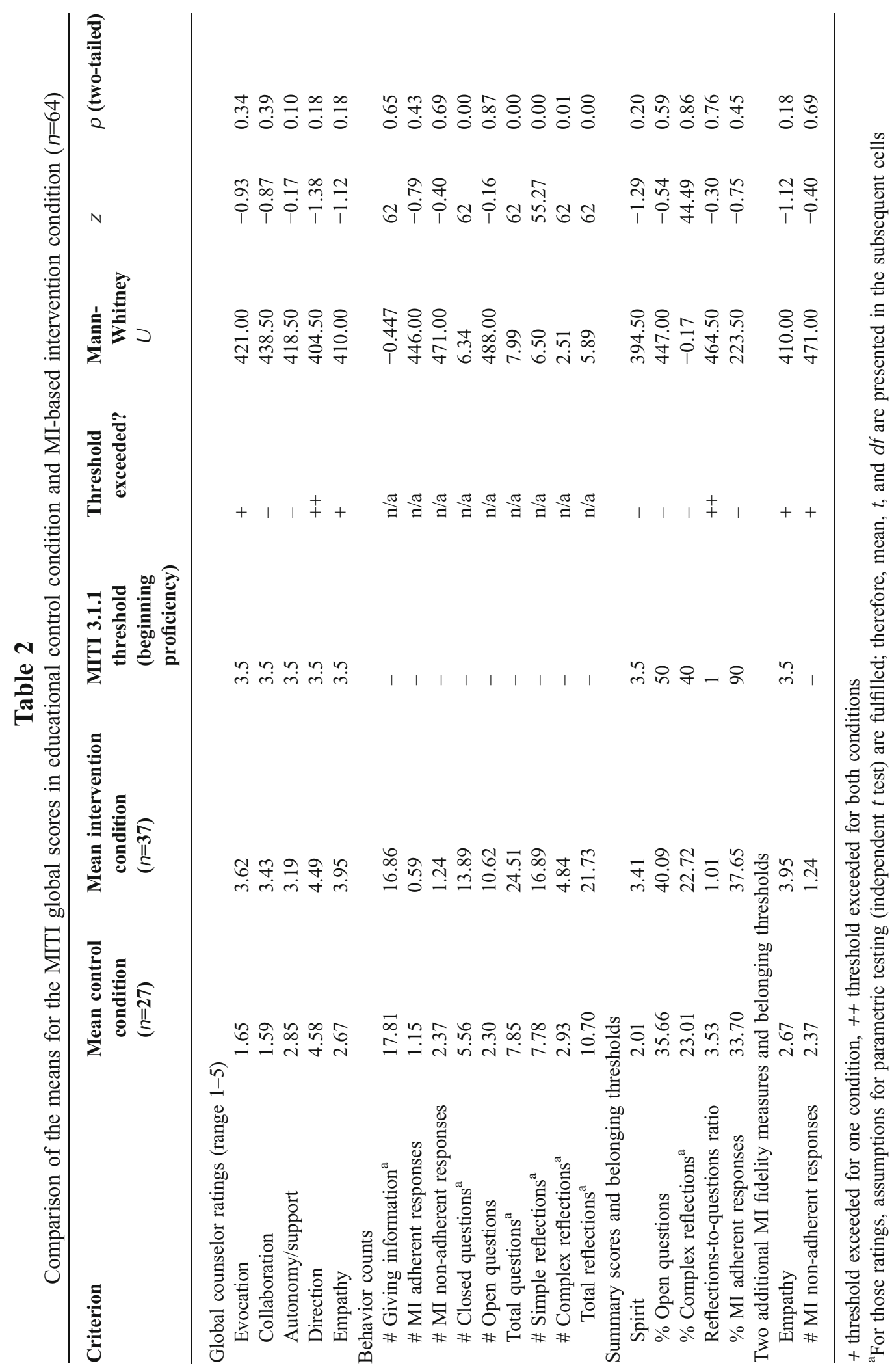


condition compared to the education control condition. However, mean differences were not statistically significantly different.

\section{Behavior counts}

The MI-based intervention condition had statistically significant higher scores for the amount of closed questions, total questions, simple reflections, complex reflections, and the amount of total reflections.

\section{Summary scores and belonging thresholds of beginning proficiency}

In terms of MI competence according to the MITI, the threshold for beginning proficiency was exceeded for the reflections-to-questions ratio only (intervention as well as control condition).

The percentage of open questions and the percentage of MI adherent responses showed slightly higher mean ratings in the intervention condition compared to the control condition (40.09 and $35.66 \%$, respectively, by a threshold of $50 \%$, and 37.65 and $33.70 \%$, respectively by a threshold of $90 \%)$.

The percentage of complex reflections ( 23.01 and $22.72 \%$, respectively, by a threshold of $40 \%$ ) as well as reflections-to-questions ratio (3.53 and 1.01, respectively) were higher in the control condition compared to the MI-based intervention condition.

\section{Two additional MI fidelity measures and belonging thresholds}

Empathy was scored higher, but not statistically different in the MI-based intervention condition, and the threshold for beginning competence was reached for the MI-based intervention.

One time less MI non-adherent responses in the intervention condition compared to the control condition were found (2.37 and 1.24, respectively).

\section{Reliability/sensitivity analysis}

Quality of reliability between the two raters was mixed (see Table 3), ranging from poor up to excellent.

The ratings of the second rater as well as the consensus approach of both raters together confirmed the previously mentioned findings of the first rater. This led to the overall conclusion that all ratings for global counselor ratings, and five out of the seven behavior count (sub)scores were in terms of MI fidelity higher in the intervention condition compared to the control condition. Similarly, it was found that not all thresholds for beginning MI proficiency were exceeded. Only in the consensus approach, a statically significant difference for the global counselor rating evocation $(<0.01)$ between the intervention and control condition was found. However, in no condition, the score did exceed the threshold in ratings of both raters.

In the consensus approach, intervention condition and control condition can be clearly discriminated for global scores spirit $(<0.01)$ and collaboration $(<0.02)$. Furthermore, the behavior counts closed questions $(<0.01)$, total questions $(<0.01)$, simple reflections $(<0.01)$, complex reflections $(<0.01)$, and total reflections $(<0.01)$ were also discriminative.

\section{Nurse-specific fidelity}

In the post hoc analysis, a considerable variation in nurses' MI fidelity of the different MITI aspects within the intervention condition and control condition was found. 
Table 3

Reliability MITI scoring for the two raters $(n=26)$

\begin{tabular}{ll}
\hline Global counselor ratings MITI & KALPHA ordinal \\
\hline Direction & 0.63 \\
Empathy & 0.55 \\
Spirit & 0.62 \\
Evocation & 0.58 \\
Collaboration & 0.57 \\
Autonomy/support & 0.17 \\
Behavior counts MITI & ICC \\
\# Giving information & $0.45^{*}$ \\
\% Open questions & $0.89^{* *}$ \\
\# Closed questions & $0.89^{* *}$ \\
\# Open questions & $0.95^{* *}$ \\
\# Total questions & $0.96^{* *}$ \\
\% Complex reflections & 0.31 \\
\# Simple reflections & $0.84^{* *}$ \\
\# Complex reflections & $0.37^{*}$ \\
\# Total reflections & $0.79^{* *}$ \\
Reflections-to-questions ratio & $0.94^{* *}$ \\
\% MI adherent responses & 0.24 \\
\# MI adherent responses & 0.12 \\
\# MI non-adherent responses & $0.41^{*}$ \\
\hline
\end{tabular}

ICC intraclass correlation coefficient, single measures, KALPHA Krippendorff's alpha $* p<0.05 ; * * p<0.01$

The nurses' individual behavior influenced the overall ratings of MI fidelity: one nurse of the control condition scored high on the reflections-to-questions ratio explaining the higher-and threshold crossing - reflections-to-questions ratio in the control condition (see Table 2).

The fact that the nurses of the intervention condition used twice as many reflections as the nurses of the control condition four times as many open questions indicated that the intervention nurses used more MI required behaviors which means that MI took place in the intervention condition. This was hidden by just looking on the summary scores and belonging thresholds.

Within the intervention group, one of the two nurses of the intervention group scored higher and crossed the threshold proficiency for two additional global counselor ratings, but did not cross another threshold of the other summary scores.

\section{Discussion}

The higher MITI mean ratings for treatment proficiency and treatment fidelity in four out of five global counselor ratings, six out of nine behavior counts, threes out of five summary scores, and two out of two additional fidelity measures confirmed that motivational interviewing was applied in the MI-based intervention condition of the underlying trial compared to its educational control condition.

MI proficiency, referred to by crossing belonging thresholds, was not present for all available domains. Furthermore, on the basis of several available domains, a statically significantly discrimination between both conditions could not be achieved. Thus, mean MI proficiency scores were higher in the MI-based intervention condition, but the levels are such that it can be debated 
whether the MI was delivered in such a way that it really influenced the patients' behavior. As such, there is concern whether the MI-based intervention is not advanced enough to make a change in the outcome of the pain rehabilitation treatment.

Sensitivity analysis by taking into account different ratings approaches (first rater, second rater, consensus approach of both raters together) seems to confirm the robustness of the findings, with the remark that these findings have to be seen in the light of rather mixed reliability. Findings of poor reliability were especially present in ratings, which did not exceed the threshold. For this reason, it cannot be concluded whether this is cause or consequence of the low reliability.

A general point of concern is that the current MITI thresholds of proficiency are based upon expert opinion, and lack empirical support. ${ }^{25}$ This implies also that it is currently unclear which level of MI is minimally required to make a change. ${ }^{33}$

Subsequently, as delivering MI is more complex than generally believed even in the case of regular and intensive training, ${ }^{34}$ an even higher level of competency than currently stated would be necessary to reach significant effects in outcome.

An explanation for the mixed findings of inter-rater reliability could be that ratings of the first and second rater did not take place in the same time span, but 3 months later, which could have led to drift (decreased intra-rater variability and increased inter-rater reliability). ${ }^{35}$ On the other hand, the robustness of the MI fidelity findings during sensitivity analysis does not indicate this.

A comparison of the current findings with that of other intervention studies using MI is hampered by the frequent use of other instruments than the MITI ${ }^{36-38}$ or the usage of the previous version MITI 1.0 or 2.0 (e.g., ${ }^{39}$ ).

In the MITI, the more important fidelity measures are either related to change talk or sustain talk or to a behavior change at a later stage. ${ }^{20}$ Therefore, important measures in the working chain of MI are (1) empathy and (2) spirit. ${ }^{40}$ Empathy, a fundamental factor in MI, although non-specific in psychotherapy, was associated with better client outcomes in MI delivered in the domain of addiction treatment. ${ }^{20}$ Spirit, which is a combination of the global scores autonomy/support, evocation, and collaboration, is a preliminary condition for change talk. ${ }^{20}$ Therein, the current finding of evocation is embedded.

In a study of Forsberg et al., it was shown that some counselors with monthly training sessions needed two and a half year to reach the level of beginning proficiency for the global variable spirit. ${ }^{35}$ In two other studies assessing MI training effects, the thresholds for spirit and empathy were exceeded immediately after the training. ${ }^{41,42}$

In the study presented, the reflections-to-questions ratio crossed the threshold for beginning proficiency and seemed also in another study easy to learn and cross. ${ }^{35}$ As a low amount of complex reflections was found in the current study, it can be concluded that it was difficult for the nurses to provide complex reflections. This was also mentioned in a study investigating MI skills and counselor characteristics before, during, and after MI training ${ }^{39}$ which is also in line with the statement that complex reflections are one of the hardest to improve skills during training. ${ }^{22,43,44}$

The current finding that MI non-adherent responses were less common in the MI-based intervention condition compared to the educational control condition is as promising as it is known that MI non-adherent counselor behaviors hinders the subsequent occurrence of change talk which predicts behavior change. ${ }^{13,18}$

Another explanation for the fact that not all MITI thresholds for beginning proficiency were crossed in the MI-based intervention condition could be due that the nurses had to follow a treatment manual since they participated in a scientific study. The usage of a manual could have resulted in a situation in which the counselor felt less free to completely focus on actual needs of the client (e.g. pushing too hard for commitment in line with the manual) resulting in a negative impact on the achieving sufficient effect sizes. ${ }^{4,45}$ 
Whereas for most of the MITI variables higher mean ratings of MITI sub scores in the MI-based intervention condition compared to the control condition were found, it could not be statistically discriminate between the two conditions for most of the MITI variables. This finding is in accordance with the study of Maissi et al. It has to be said that some of the before mentioned studies did not use the MITI to discriminate between conditions at all; thus, they were not included in this comparison. ${ }^{15,43,44}$ Only one study indeed provided differences in MITI scores between MI conditions. ${ }^{41}$

The current findings of differences in MI fidelity on nurse level in the intervention condition in the post-hoc analysis are in line with a study on MI training effects, which also showed a broad variation in counselor functioning ${ }^{46}$ and fluctuations over time. ${ }^{35}$

In addition, it seems that some counselors are not able to acquire skills ${ }^{34,47}$ whereas others may easily learn the new technique, no matter the extent of training provided. This inter-person difference is in line with findings of this study and also with some other studies in the field of the effects of MI-training. ${ }^{35,48,49}$ As a consequence, a stricter selection policy (e.g., for empathy) before entry as a potential solution for undesired variations in counselors' MI functioning is advocated. ${ }^{47}$ In addition, future study results should enlighten the most effective MI training approaches as the important role of continuous supervision and feedback for MI practitioners is also reported elsewhere. ${ }^{39}$

Although in a systematic review of O'Halloran et al., higher results for the effectiveness of MI intervention were yielded if fidelity assessment had taken place, ${ }^{12}$ Lundahl et al. reported in contrast in their systematic review that checking MI fidelity was inversely related to MI outcomes. ${ }^{5}$ This was a surprising outcome, and those findings have to be seen in the light of two comments $^{50,51}$ regarding methodological aspects of this review published. Apart from that, in accordance with Lundahl et al., ${ }^{5}$ future studies are necessary and recommended to find an explanation for this phenomenon. The results of the underlying trial of this current study will be available next year and hopefully will shed some more light on this topic.

Although several studies investigating MI fidelity do not even mention reliability between two or more raters, ${ }^{44,52}$ results of the present and other studies (e.g., ${ }^{41,46}$ ) seem to underscore that a study of rater reliability is required and the procedure has to include regular rater meetings to prevent rater drift and probably prevent to hamper reliability. ${ }^{27}$

At this moment, two overviews are available who describe a tool for treatment fidelity in health behavior change trials, ${ }^{53}$ and in trials using motivational interviewing specifically. ${ }^{54}$

Furthermore, several instruments are available for the assessment of MI quality. The MITI has shown to have good inter-rater reliability ${ }^{27}$ and predictive validity, ${ }^{28}$ and seems the most suitable if the specific focus is to specifically evaluate counselor behavior.

Furthermore, a limitation in the use of the MITI is that complex therapist (counselor) competence such as intentional or strategic use of MI may be insufficiently assessed ${ }^{55}$ and one cannot evaluate the timing of interventions and techniques ${ }^{56}$ as well as that the MITI does not take into account the context in which an interview takes place. A second limitation is the very time consuming coding of the sessions by means of the MITI; intensive training of the raters and continuous consulting between raters on intervention-specific topics and MITI-specific rating topics is necessary in order to rate unanimously.

Some limitations of the present study need to be considered. First, the fidelity of the nurses in the MI intervention condition prior to or at the start of the trial was not assessed. This could have flawed the effectiveness of MI training and also the overall effectiveness of the MI intervention. Second, the first rater was not blinded for treatment allocation in the intervention versus control condition, which could have hampered validity of the findings. However, the finding that the blinded second rater confirmed the first rater's findings invalidates this supposition. 


\section{Conclusion}

In general higher levels of MI fidelity in the intervention condition were found as well as were it possible to partially discriminate between MI-based intervention and education-based control condition. Although the quality of MI delivery as well as mixed inter-rater reliabilities of the fidelity scores leaves room for improvement, robust findings between the two raters and also their consensus approach were found.

Further analyses of the long-term effectiveness of the underlying trial will show whether a MIbased pre-treatment is more effective compared to a pain education pre-treatment and whether this improves participation and functioning of patients with fibromyalgia and chronic musculoskeletal pain undergoing pain rehabilitation.

\section{Implications for Behavioral Health}

The present study confirms the need for rigor selection of MI counselors before training, and the important role of continuous supervision and feedback for MI practitioners in order to reach proper MI fidelity as well as the need for fidelity check in studies using MI.

\section{Acknowledgments}

The research was funded by Adelante, the Department of Rehabilitation Medicine, Maastricht University, and in addition by a travel grant of the Dutch Arthritis Foundation (reumafonds). All authors worked independently of the funding body, and funding had no role in the collection, analysis, interpretation, writing or decision to submit this article. Coding of VCM took place during a research visit at the MIC lab of the Karolinska Institutet, Stockholm, Sweden. The authors would also like to thank the whole team of the MIC lab. The considerable advice and coding as second rater of Judith Jelsma (JJ) is gratefully acknowledged. Draft versions of some results were presented at the International Conference on Motivational Interviewing in Amsterdam, the Netherlands, 18 June 2014.

\section{Compliance with Ethical Standards}

Conflict of Interest There is no conflict of interest.

Open Access This article is distributed under the terms of the Creative Commons Attribution 4.0 International License (http://creativecommons.org/licenses/by/4.0/), which permits unrestricted use, distribution, and reproduction in any medium, provided you give appropriate credit to the original author(s) and the source, provide a link to the Creative Commons license, and indicate if changes were made.

\section{References}

1. Miller WR, Rollnick S. Ten things that motivational interviewing is not. Behavioural and Cognitive Psychotherapy. 2009;37(2):129-140.

2. Solomon DH, Iversen MD, Avorn J, et al. Osteoporosis telephonic intervention to improve medication regimen adherence: a large, pragmatic, randomized controlled trial. Archives of Internal Medicine. 2012;172(6):477-483.

3. Burke B, Arkowitz H, Menchola M. The efficacy of motivational interviewing: a meta-analysis of controlled clinical trials. Journal of Consulting and Clinical Psychology. 2003;71(5):843-861.

4. Hettema J, Steele J, Miller WR. Motivational interviewing. Annual Review of Clinical Psychology. 2005;1:91-111.

5. Lundahl B, Moleni T, Burke BL, et al. Motivational interviewing in medical care settings: a systematic review and meta-analysis of 
randomized controlled trials. Patient Education and Counseling. 2013;93(2):157-168.

6. Rubak S, Sandbaek A, Lauritzen T, et al. Motivational interviewing: a systematic review and meta-analysis. British Journal of General Practice. 2005;55(513):305-312.

7. Lundahl B, Burke BL. The effectiveness and applicability of motivational interviewing: A practice-friendly review of four meta-analyses. Journal of Clinical Psychology. 2009;65(11):1232-1245.

8. Ang DC, Kaleth AS, Bigatti S, et al. Research to encourage exercise for Fibromyalgia (REEF): Use of motivational interviewing design and method. Contemporary Clinical Trials. 2010.

9. Habib S, Morrissey S, Helmes E. Preparing for pain management: a pilot study to enhance engagement. Journal of Pain. 2005;6(1):48-54.

10. Leonhardt C, Keller S, Chenot JF, et al. TTM-based motivational counselling does not increase physical activity of low back pain patients in a primary care setting-A cluster-randomized controlled trial. Patient Education and Counseling. 2008;70(1):50-60.

11. Vong SK, Cheing GL, Chan F, et al. Motivational enhancement therapy in addition to physical therapy improves motivational factors and treatment outcomes in people with low back pain: a randomized controlled trial. Archives of Physical Medicine and Rehabilitation. 2011;92(2):176-183.

12. O'Halloran PD, Blackstock F, Shields N, et al. Motivational interviewing to increase physical activity in people with chronic health conditions: a systematic review and meta-analysis. Clinical Rehabilitation. 2014

13. Miller WR, Rose GS. Toward a theory of motivational interviewing. American Psychologist. 2009;64(6):527-537.

14. Rollnick S, Butler CC, Kinnersley P, Gregory J, Mash B. Motivational interviewing British Medical Journal. $2010 ; 340$.

15. Gaume J, Bertholet N, Faouzi M, et al. Counselor motivational interviewing skills and young adult change talk articulation during brief motivational interventions. Journal of Substance Abuse Treatment. 2010;39(3):272-281.

16. Bellg AJ, Borrelli B, Resnick B, et al. Enhancing treatment fidelity in health behavior change studies: best practices and recommendations from the NIH Behavior Change Consortium. Health Psychology. 2004;23(5):443-451.

17. Perepletchikova F, Treat TA, Kazdin AE. Treatment integrity in psychotherapy research: analysis of the studies and examination of the associated factors. Journal of Consulting and Clinical Psychology. 2007;75(6):829-841.

18. Moyers TB, Martin T. Therapist influence on client language during motivational interviewing sessions. Journal of Substance Abuse Treatment. 2006;30(3):245-251.

19. Lovejoy TI, Heckman TG, Suhr JA, et al. Telephone-administered motivational interviewing reduces risky sexual behavior in HIVpositive late middle-age and older adults: a pilot randomized controlled trial. AIDS and Behavior. 2011;15(8):1623-1634.

20. Apodaca TR, Longabaugh R. Mechanisms of change in motivational interviewing: a review and preliminary evaluation of the evidence. Addiction. 2009;104(5):705-715.

21. Miller W, Mount K. A small study of training in motivational interviewing: does one workshop change clinician and client behavior? Behavioral and Cognitive Psychotherapy. 2001;29:457-471.

22. Miller W, Yahne C, Moyers T, et al. A randomized trial of methods to help clinicians learn motivational interviewing. Journal of Consulting and Clinical Psychology. 2004;72(6):1050-1062.

23. Moyers TB, Martin T, Manuel JK, et al. Assessing competence in the use of motivational interviewing. Journal of Substance Abuse Treatment. 2005;28(1):19-26.

24. Mertens VC, Goossens ME, Verbunt JA, et al. Effects of nurse-led motivational interviewing of patients with chronic musculoskeletal pain in preparation of rehabilitation treatment (PREPARE) on societal participation, attendance level, and cost-effectiveness: study protocol for a randomized controlled trial. Trials. 2013;14(1):90.

25. Moyers TB, Martin T, Manuel JK, et al. Revised Global Scales: Motivational Interviewing Treatment Integrity 3.1.1 (MITI 3.1.1). 2010. Available online at: http://casaa.unm.edu/download/MITI3_1.pdf. Accessed on September 12, 2015.

26. Pierson HM, Hayes SC, Gifford EV, et al. An examination of the Motivational Interviewing Treatment Integrity code. Journal of Substance Abuse Treatment. 2007;32(1):11-17.

27. Forsberg L, Kallmen H, Hermansson U, et al. Coding counsellor behaviour in motivational interviewing sessions: inter-rater reliability for the Swedish Motivational Interviewing Treatment Integrity Code (MITI). Cognitive Behaviour Therapy. 2007;36(3):162-169.

28. Forsberg L, Berman AH, Kallmen H, et al. A test of the validity of the Motivational Interviewing Treatment Integrity Code. Cognitive Behaviour Therapy. 2008;37(3):1-9.

29. Moyers TB, Miller WR. Is low therapist empathy toxic? Psychology of Addictive Behaviors. 2013;27(3):878-884

30. Cicchetti DV. Guidelines, criteria, and rules of thumb for evaluating normed and standardized assessment instruments in psychology. Psychological Assessment. 1994;6(4):284-290.

31. Krippendorff K. Agreement and Information in the Reliability of Coding. Communication Methods and Measures. 2011;5(2):93-112.

32. Hayes AF, Krippendorff K. Answering the Call for a Standard Reliability Measure for Coding Data. Communication Methods and Measures. 2007;1(1):77-89.

33. Miller WR, Rollnick S. The effectiveness and ineffectiveness of complex behavioral interventions: Impact of treatment fidelity. Contemporary Clinical Trials. 2014;37(2):234-241.

34. Bohman B, Forsberg L, Ghaderi A, et al. An Evaluation of Training in Motivational Interviewing for Nurses in Child Health Services. Behavioural and Cognitive Psychotherapy. 2013;41(03):329-343.

35. Forsberg L, Forsberg LG, Lindqvist H, et al. Clinician acquisition and retention of Motivational Interviewing skills: a two-and-a-half-year exploratory study. Substance Abuse Treatment, Prevention, and Policy. 2010;5:8.

36. Zwikker HE, van den Ende CH, van Lankveld WG, et al. Effectiveness of a group-based intervention to change medication beliefs and improve medication adherence in patients with rheumatoid arthritis: A randomized controlled trial. Patient Education and Counseling. 2014;94(3):356-361.

37. Noordman J, de Vet E, van der Weijden T, et al. Motivational interviewing within the different stages of change: An analysis of practice nurse-patient consultations aimed at promoting a healthier lifestyle. Social Science \& Medicine. 2013;87(0):60-67. 
38. Jansink R, Braspenning J, Van Der W, et al. Nurse-led motivational interviewing to change the lifestyle of patients with type 2 diabetes (MILD-project): protocol for a cluster, randomized, controlled trial on implementing lifestyle recommendations. BMC Health Service Research. 2009;9:19.

39. Carpenter KM, Cheng WY, Smith JL, et al. "Old dogs" and new skills: how clinician characteristics relate to motivational interviewing skills before, during, and after training. Journal of Consulting and Clinical Psychology. 2012;80(4):560-573.

40. Miller WR, Rollnick S. Motivational Interviewing: Preparing People for Change. (Second Ed.) ed. New York: The Guilford Press; 2002.

41. Daeppen JB, Fortini C, Bertholet N, et al. Training medical students to conduct motivational interviewing: a randomized controlled trial. Patient Education and Counseling. 2012;87(3):313-318.

42. Maissi E, Ridge K, Treasure J, et al. Nurse-led psychological interventions to improve diabetes control: assessing competencies. Patient Education and Counseling. 2011;84(2):e37-43.

43. Baer JS, Rosengren DB, Dunn CW, Wells EA, Ogle RL, Hartzler B. An evaluation of workshop training in motivational interviewing for addiction and mental health clinicians. Drug and Alcohol Dependency. 2004;73(1):99-106.

44. Van Eijk-Hustings YJL, Daemen L, Schaper NC, et al. Implementation of Motivational Interviewing in a diabetes care management initiative in the Netherlands. Patient Education and Counseling. 2011;84(1):10-15.

45. Lundahl BW, Kunz C, Brownell C, et al. A meta-analysis of motivational interviewing: Twenty-five years of empirical studies. Research on Social Work Practice. 2010;20(2):137-160.

46. Maissi E, Ridge K, Treasure J, et al. Nurse-led psychological interventions to improve diabetes control: assessing competencies. Patient Education and Counseling. 2011;84(2):37-43.

47. Lindhardt CL, Rubak S, Mogensen O, et al. Training in motivational interviewing in obstetrics: a quantitative analytical tool. Acta Obstetricia et Gynecologica Scandinavica. 2014;93(7):698-704.

48. Miller WR, Moyers TB, Arciniega L, et al. Training, supervision and quality monitoring of the COMBINE Study behavioral interventions. Journal of Studies on Alcohol and Drugs. Suppl. 2005(15):188-195; discussion 168-189.

49. Moyers TB, Manuel JK, Wilson PG, et al. A Randomized Trial Investigating Training in Motivational Interviewing for Behavioral Health Providers. Behavioural and Cognitive Psychotherapy. 2008;36(02):149-162.

50. Mullin D. Seeking clarification and corrections of motivational interviewing meta-analysis. Patient Education and Counseling. 2014;95(2):295.

51. Van der Wouden JC, Rietmeijer C. Motivational interviewing in the medical care setting. Patient Education and Counseling 2014;96(1):142

52. Robbins LB, Pfeiffer KA, Maier KS, et al. Treatment fidelity of motivational interviewing delivered by a school nurse to increase girls' physical activity. Journal of School Nursing. 2012;28(1):70-78.

53. Borrelli B. The Assessment, Monitoring, and Enhancement of Treatment Fidelity In Public Health Clinical Trials. Journal of Public Health Dentistry. 2011;71(s1):S52-S63.

54. Jelsma JG, Mertens VC, Forsberg L, et al. How to Measure Motivational Interviewing Fidelity in Randomized Controlled Trials: Practical Recommendations. Contemporary Clinical Trials. 2015;43:93-99.

55. Madson MB, Campbell TC. Measures of fidelity in motivational enhancement: a systematic review. Journal of Substance Abuse Treatment. 2006;31(1):67-73.

56. de Jonge JM, Schippers GM, Schaap CPDR. The Motivational Interviewing Skill Code: Reliability and a Critical Appraisal. Behavioural and Cognitive Psychotherapy. 2005;33(03):285-298. 